\title{
Varia
}

\section{"Danza da lúa en Santiago". Suxerencias para unha aproximación a Federico García Lorca, poeta galego (1985)}

\author{
María Victoria MoReno \\ Xesús Alonso Montero \\ Universidade de Santiago de Compostela \\ Real Academia Galega
}

E unha nota introdutoria non innecesaria

\section{NOTA INTRODUTORIA}

Hai dez anos que faleceu María Victoria Moreno Márquez, aquela gran narradora, aquela excelente lectora, aquela extraordinaria profesora. Aínda quedan ecos elocuentes das súas palabras maxistrais nas aulas do Instituto masculino de Lugo (hoxe denominado "Lucus Augusti"). Alí se estreou nos sesenta como profesora de Literatura, alí nos coñecemos e alí a miña familia soubo, desde o primeiro día, da súa bondade, da súa cultura e da súa xenerosidade. Cando se trasladou, profesionalmente, a Pontevedra, xa deixara en Lugo un grupo de alumnos que amaban os libros; algúns, como Xesús Rábade Paredes, incipientes escritores. María Victoria fóisenos hai dez anos: o 21 de novembro de 2005. Acababa de cumprir sesenta e catro anos. En Pontevedra, onde residía, aínda se percibe, vigoroso, o ronsel de admiración e gratitude que deixou aquela extraordinaria profesora, aquela profesora tan humana, tan pedagoga. Vivía a Literatura e transmitíaa.

No eido das Letras, ademais de narradora, é autora dunha antoloxía histórica que eu lle publiquei na colección Arealonga, de Akal Editor (Madrid): Os novísimos da poesía galega (1973); tamén é autora dun exemplar libro de texto para $\mathrm{COU}$, no que colaborou Xesús Rábade Paredes, o seu exalumno: $L i$ teratura - Século XX. Iniciación universitaria (Galaxia/Ediciones SM, 1985).

Ese volume contén oito páxinas nas que María Victoria comenta "Cantiga do neno da tenda", o terceiro dos Seis poemas galegos de Lorca (Santiago, Nós, 1935). É unha incitante lección na que sitúa o poema dentro das coordenadas doutros libros de Federico como unha peza máis, nunca inferior, do universo poético lorquiano.

Sabedor eu desta devoción literaria de María Victoria, convideina para que impartise un breve curso sobre Lorca (como poeta galego) na Escola de Verán en setembro de 1981 (Pontevedra). Centrouse en "Danza da lúa en Santiago", o sexto dos poemas do inesquecible hexaedro literario de Federico. Conservo as fichas do cursiño, que son oito, con versos e exemplos moi acaídos de Romancero gitano e outros libros de Lorca, preludio do que atoparemos no volume de 1985 .

Foi nese ano, cincuentenario da primeira edición dos Seis poemas galegos, cando lle pedín, para unha obra colectiva que estaba a deseñar, un traballo (un comentario) sobre os 
Seis poemas, traballo que tardou un ano grosso modo en entregarmo. Nunha nota preliminar, manuscrita, María Victoria, sempre tan educada, pide desculpas pola breve tardanza. Nesa mesma nota adianta:

O propósito - seica non logrado, que non sabes cómo andaba eu cando o escribín- é dar algún argumento de que os Seis poemas galegos teñen o seu punto de partida no mesmo mundo poético que o resto da obra de Federico García Lorca. Coido que por este vieiro hai posibilidades de chegar a un argumento definitivo contra os falacios de Guerra Dacal.

Gardei como ouro en pano o mecanoscrito de María Victoria. Gardeino tanto que ese opúsculo de vinte folios estivo, na "turbamulta" dos meus papeis, extraviado. Cando, hai poucos meses, batín con el nunha insospeitada

Federico García Lorca, que naceu en Fuente Vaqueros en 1898 e foi asasinado no camiño de Víznar en 1936, escribe os Seis poemas galegos a partir das viaxes que fixo a Galicia en 1932. O autor deste breve poemario é, xa que logo, un home que ten aproximadamente trinta e cinco anos, que conta no seu haber cunha brillante traxectoria poética e que está a vivir, coa gozosa intensidade de sentirse parte integrante do cosmos, os derradeiros anos da súa vida.

Non faríamos unha boa lectura do Lorca poeta galego se non contextualizásemo-los Seis poemas galegos no conxunto da traxectoria do seu autor e se non tomásemos como punto de referencia o mundo poético que este posuía cando veu a Galicia en 1932. Porque

la vie psychologique -dicía Bergson- n'est pas une poussiere d'atomes, mais une succession d'états dont chacun annonce ce qui suit et contient en lui ce que précede. Un courant de sentiment qui traverserait le spectre en se teignant tour à tour de chacune de ses nuances, éprouverait les changements graduels dont chacun annoncerait le suivant et résumirait en lui ceux qui le précèdent. carpeta, levei a grande alegría bibliográfica da miña vida. O que tiña que ser publicado, cando menos, no primeiro cabodano de María Victoria, como homenaxe, cúmprese agora, no décimo, mercé á xenerosidade da revista $\mathrm{Ma}$ drygal e os bos oficios de Carmen Mejía.

$\mathrm{Eu}$ non tardarei en redactar unha pequena monografía sobre María Victoria Moreno Márquez, a quen moitos en Galicia queremos, admiramos e choramos. Sabido é que María Victoria é foránea: naceu en Valencia de Alcántara (Cáceres) no ano 1941, estudou na Universidade de Madrid e, xa adulta, mergullouse, en principio desde Lugo, nas inquedanzas e nas Letras de Galicia. De feito, como escritora, é unha escritora alófona como Lorca, tan no país que a súa voz, máis que alófona, é autófona.

\section{Xesús Alonso Montero Vigo, setembro 2015}

A cifra elucidadora da autoría e así mesmo do significado dos Seis poemas galegos debe procurarse, pois, na obra lorquiana anterior a 1932.

Iníciase Federico García Lorca como poeta no Libro de poemas, obra primeiriza, escrita nos arredores dos vinte anos e pouco representativa do que vai se-la súa producción posterior. Hai neste libro unha inxel preocupación metafísica que non interesa; percíbese doadamente a traza de poetas como Juan Ramón Jiménez, Antonio Machado ou Rubén Darío, e o único dato positivo é a autocrítica, a expresión do desacougo que produce a Federico saberse poeta e ser consciente de non dar atopado saída orixinal para a súa voz:

$$
\begin{aligned}
& \text { ¡Oh, qué dolor, el tener } \\
& \text { versos en la lejanía } \\
& \text { de la pasión y el cerebro } \\
& \text { todo manchado de tinta! }
\end{aligned}
$$

A linguaxe poética, que vai ser unha das facetas xeniais do Lorca maduro, amósase neste libro como resultado dunha longa operación intelectual: 
El diamante de una estrella

ha rayado el hondo cielo.

E o instinto do popular, se cadra a aptitude persoal máis característica do granadino, tan só se albisca de cando en vez, máis como proxecto que como logro.

Entre os anos 1921 e 1924 aparecen dous libros que, conxuntamente, marcan un importante avance na maduración do poeta e, polo tanto, un considerable achegamento ó que vai se-lo autor dos Seis poemas galegos. Son estes libros Poema del cante jondo e Canciones.

Poema del cante jondo é xa un libro orixinal e espontáneo. Polos vieiros do andalucismo acada unha fondura impensable desde o Libro de poemas e o autor familiarízase coas voces secretas do cosmos, que transmite xa maxistralmente. Sérvese das figuras do cante flamenco (siguiriya, soleá, saeta, petenera) para amosar unha vida axexada pola morte: como descobre M. J. Flys, non describe as figuras senón que intúe e traduce a tensión contida nelas. Por iso todo o libro é a vibración que corresponde a esta tensión:

Tiembla junco y penumbra
a la orilla del río.
Se eriza el aire gris.
Los olivos
están cargados
de gritos.
Una bandada
de pájaros cautivos
que mueven sus larguísimas
colas en lo sombrío.

Canciones é un libro artístico, fortemente vencellado ó ultraísmo, a moda literaria no Madrid dos primeiros anos vinte, que se irradiaba desde a Residencia de Estudiantes, da Institución Libre de Enseñanza, frecuentada daquela por figuras tan relevantes da avangarda artística española como Salvador Dalí, Luis Buñuel e o propio García Lorca.

O ultraísmo, procurando unha arte artística, deshumanizada, elimina do poema a anécdota, a efusión sentimental, a confesionalidade e maila linguaxe poética convencional. $\mathrm{O}$ resultado é unha resposta breve, caracterizada pola instantaneidade e a audacia expresiva: a imaxe, innovadora coma un refacho de aire limpo, convertirase no núcleo desta resposta, a sorpresa será a alma do poema e a metáfora o vieiro máis frecuente de expresión.

A adhesión de Federico García Lorca ó ultraísmo faino saír definitivamente das elaboracións intelectuais do Libro de poemas e encamíñao xa á xenialidade expresiva do $R o$ mancero gitano:

En la luna negra de los bandoleros, cantan las espuelas.

Caballito negro, ¿Dónde llevas tu jinete muerto?

...Las duras espuelas del bandido inmóvil que perdió las riendas.

Caballito frío, ¡Qué perfume de flor de cuchillo!

En la luna negra sangraba el costado de Sierra Morena.

Caballito negro, ¿Dónde llevas tu jinete muerto?

La noche espolea sus negros ijares clavándose estrellas.

Caballito frío, ¡Qué perfume de flor de cuchillo!

En la luna negra, ¡un grito! y el cuerno largo de la hoguera.

Caballito negro, ¿Dónde llevas tu jinete muerto?

O Romancero gitano representa a culminación da que podemos chamar etapa andaluza de Federico García Lorca. Neste libro conflúen xenialmente os acertos de Poema del cante jondo e Canciones. Prodúcese unha plena identificación co cosmos e coas súas forzas en liberdade, representadas polo xitano, ó mesmo tempo que unha linguaxe literaria insolitamente eficaz transmuta as entidades abstractas do pensamento e do sentimento en sensacións: 
Visuais:

Sobre el rostro del aljibe se mecía la gitana.

Verde carne, pelo verde, con ojos de fría plata.

Un carámbano de luna

la sostiene sobre el agua.

Auditivas:

Las piquetas de los gallos cavan buscando la aurora, cuando por el monte oscuro baja Soledad Montoya.

Tactís:

La tarde loca de higueras $\mathrm{y}$ de rumores calientes cae desmayada en los muslos heridos de los jinetes

Olfativas:

Trescientas rosas morenas lleva tu pechera blanca.

Tu sangre rezuma y huele alrededor de tu faja.

Gustativas:

Los dos compadres subieron.

El largo viento dejaba

en la boca un raro gusto

de hiel, de menta y de albahaca.

$* * *$

Federico García Lorca atópase ó escribir en galego en situación semellante á dos vellos trovadores dos Cancioneiros medievais: estes, por se expresaren nunha coiné, renunciaban deliberadamente á riqueza léxica e gramatical das súas respectivas linguas locais. Aquel, por poetizar nunha lingua que non coñecía, impúxose, seica tamén deliberadamente, severas restriccións en recursos expresivos. Mais o resultado final destes actos de creación é sempre positivo: os trovadores acertaron a expresa-la esencia lírica con transparencia e acharon os artificios axeitados ós seus condicionantes servíndose da recurrencia. A propia estrofa paralelística, representativa da escola, é exemplo de como a coiné supoñía unha unanimidade de criterios que ía máis alá do estrictamente léxico e gramatical:

Seria-m'eu na ermida de Sam Simhon, e cercarom-m'as ondas, que grandes som, en atendend'o meu amigo!

Estando na ermida, ant'o altar, cercarom-m'as ondas grandes do mar, en atendend'o meu amigo!

(Meendiño)

E o leixaprén, por medio do cal se encadean e acadan unidade na súa progresión as distintas estrofas dunha cantiga, é outro procedemento establecido sobre a recurrencia:

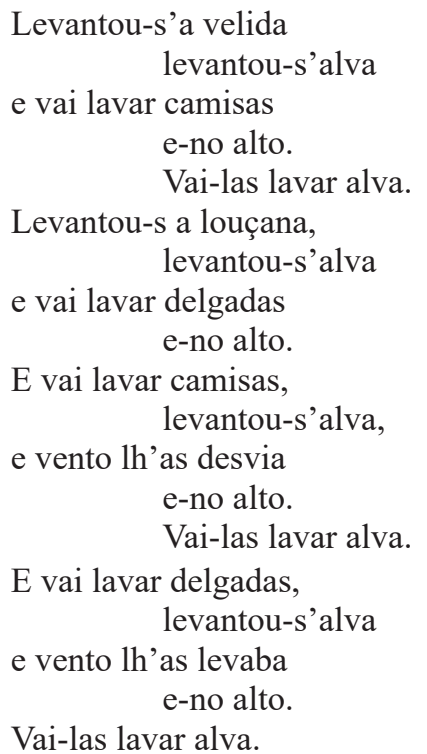

(Don Denís)

Federico García Lorca crea tamén nos Seis poemas galegos un mundo poético, sinxelo e transparente, onde a realidade se transmuta en virtude dunha percepción orixinal e dunha brillante intuición lírica que leva ó autor do Romancero gitano á utilización dunha retórica semellante á empregada polos trovadores medievais. En efecto, as figuras máis doadamente perceptibles no poemario que nos ocupa (repeticións, anáforas, paralelismos, refráns, concatenacións) teñen a súa base no emprego artístico da recurrencia e permítenlle ó autor obte-los matices expresivos desexados utilizando un corpus léxico e gramatical moi limitado: 
Os arados van e vén

dende Santiago a Belén.

Dende Belén a Santiago

un anxo vén en un barco.

Un barco de prata fina

que trai a door de Galicia.

$\mathrm{Na}$ obra dun poeta como Lorca, que recoñeceu deberlle os seus acertos ás dotes innatas e mais ó traballo, é difícil determinar en que medida cada parcela da súa producción se debe á intuición espontánea ou á reflexión consciente. Por isto, no caso dos Seis poemas galegos, quédano-la dúbida de se as características que rematamos de ver -non de todo descoñecidas na obra lorquiana en castelánson independentes da relación que mantivo o poeta coa literatura galega de avangarda, ou se están condicionadas por ela. En todo caso, cómpre lembrar que a partir de 1926-1928, data da edición das Cantigas de amigo preparada por José Joaquim Nunes, a lírica medieval acada nova vixencia en Galicia e orixina a aparición do neotrovadorismo, escola fundada por Fermín Bouza Brei e seguida por Álvaro Cunqueiro, Xosé María Álvarez Blázquez e Eduardo Blanco Amor, amigo persoal de Lorca e prologuista dos Seis poemas galegos.

Deste xeito, aínda sen sabermos con certeza onde reside a explicación, descubrímo-la lexitimidade de Federico García Lorca como poeta galego no seu entronque coa mellor e máis vella tradición lírica do país e, ó mesmo tempo, coa escola de avangarda que tiña máis seguidores e máis vixencia entre os poetas galegos de 1932, que se expresaban deste xeito:

Polos teus ollos quen pasou, amiga, deixou unha ollada de amore perdida. Nos teus ollos.

Deixou de amore perdida unha ollada polos teus ollos quen pasou, amada.

Nos teus ollos.

Cinza levás nos ollos, amiga, daquela ollada de amore perdida. Nos teus ollos.

Borrallo nos ollos levás, amada, que non miraches a quen te ollaba. Nos teus ollos.

(Álvaro Cunqueiro)
A outra faceta da lexitimidade dos Seis poemas galegos reside no feito de que se integran perfectamente na obra lorquiana anterior a 1932 .

Aínda que o profesor Carballo Calero opina que este poemario se atopa na liña de Canciones, parécenos axeitado entender que se produciu a partir do Romancero gitano, tanto pola data da súa escritura como polo peculiar universo poético que se amosa nel.

Ese mundo de sensacións característico do Romancero, no que pensamento e sentimento quedan traducidos a entidades concretas perceptibles polos sentidos, é o mesmo dos Seis poemas galegos, onde non hai nada abstracto, nada alleo á relación intensa entre o poeta e o cosmos, nada que se poida explicar desde un código distinto do que naceu para canta-las forzas da natureza en liberdade e a vida do home no seu estado natural de dependencia do acontecer cósmico.

Un poeta andaluz matizou, en 1928, a diferente actitude de dous xitanos mozos ante o amor concretizando deste xeito a intensidade da entrega de cada un deles:
Yo me quité la corbata.
Ella se quitó el vestido.
Yo el cinturón con revólver.
Ella sus cuatro corpiños.

E este mesmo poeta, galego en 1932, segue idéntico procedemento concretizador para dar saída á súa conmoción ante o espírito dos pobos que ven morre-lo sol no seu mar. En versos que aluden simultaneamente á paisaxe, ó clima e ó paso do tempo polas seculares pedras de Compostela, exprésase así no Madrigal á cibdá de Santiago:

Soma e cinza do teu mar

Santiago, lonxe do sol.

Ágoa da mañán anterga

trema no meu corazón.

Na Cantiga do neno da tenda valórase a saudade do emigrante galego en versos coma estes:

¡Triste Ramón de Sismundi!

Sinteu a muiñeira de ágoa

mentres sete bois de lúa

pacían na súa lembranza. 
Tamén este poeta recolle do ambiente que se respira en Galicia a mitificación de que é obxecto Rosalía de Castro e conságraa despois establecendo un paralelismo entre a autora de Follas novas e Cristo. Este paralelismo, que de seu é conceptual, faise perceptible visualmente na Canzón de cuna pra Rosalía Castro, morta:

Os arados van e vén

dende Santiago a Belén.

Dende Belén a Santiago

un anxo vén en un barco.

No Romancero gitano perfílase un mundo arquetípico doadamente identificable por unha peculiar mitoloxía de cabalos, coitelos, flores, froitos, auga e lúa. Esta mitoloxía, valedía para a representación da relación entre o home e o cosmos, repítese nos Seis poemas galegos, considerablemente reducida e simplificada a causa da brevidade do poemario e das circunstancias da súa escritura. A auga e a lúa son os elementos desta mitoloxía que pasan do $R o$ mancero gitano ós Seis poemas galegos, mantendo nesta obra idéntica natureza e función. A esta escena de morte do "Romance sonámbulo":

Sobre el rostro del aljibe se mecía la gitana.

Verde carne, pelo verde, con ojos de fría plata.

Un carámbano de luna

la sostiene sobre el agua.

A esta escena, diciamos, corresponde outra, moi semellante na súa estética e na súa mitoloxía, do "Noiturnio do adoescente morto":

Súa i-alma choraba, ferida e pequena embaixo os arumes de pino e de herbas.

Ágoa despenada baixaba da lúa cobrindo de lírios a montana núa.

Dous dos Seis poemas galegos teñen a morte como tema: o "Noiturnio do adoescente morto" e a "Danza da lúa en Santiago". Nos dous está presente a lúa e nos dous axústase perfectamente no seu tratamento ó paradigma trazado no Romancero gitano. Símbolo estético que preside o ritual do pasamento e sinal do cosmos que adverte da presencia da morte, a lúa dos Seis poemas galegos amósase sempre coas características dunha divinidade de dúas faces: a visible, que enfeitiza pola súa fermosura, e a oculta, que sobrecolle polo seu misterio:

¡Fita aquel branco galán, olla seu transido corpo!

É a lúa que baila na Quintana dos mortos.

Fita seu corpo transido negro de sombras e lobos.

Nai: a lúa está bailando na Quintana dos mortos.

¿Quen fire potro de pedra na mesma porta do sono?

¡É a lúa! ¡É a lúa! na Quintana dos mortos.

¿Quen fita meus grises vidros cheos de nubens seus ollos?

¡É a lúa! ¡É a lúa! na Quintana dos mortos.

Déixame morrer no leito soñando con flores de ouro.

Nai: a lúa está bailando na Quintana dos mortos.

¡Ai filla, co ar do ceo vólvome branca de pronto!

Non é o ar, é a triste lúa na Quintana dos mortos.

¿Quen brúa co-este xemido de inmenso boi melancónico?

Nai: é a lúa, é a lúa na Quintana dos mortos.
¡Si, a lúa, a lúa coronada de toxos,
que baila, e baila, e baila na Quintana dos mortos!

A "Danza da lúa en Santiago" é unha danza da morte na que a actitude didáctica e moralizante, característica dos textos franceses medievais e do manuscrito castelán de El Escorial, está sustituída por unha actitude estética. 
O precedente máis inmediato deste poema atópase no Romancero gitano, concretamente no "Romance de la luna, luna", que é unha danza da morte de idénticas características.

La luna vino a la fragua

con su polisón de nardos.

El niño la mira mira.

El niño la está mirando.

En el aire conmovido

mueve la luna sus brazos

y enseña, lúbrica y pura,

sus senos de duro estaño.

Huye, luna, luna, luna.

Si vinieran los gitanos,

harían con tu corazón

collares y anillos blancos.

Niño, déjame que baile.

Cuando vengan los gitanos,

te encontrarán sobre el yunque

con los ojillos cerrados.

Huye, luna, luna, luna,

que ya siento sus caballos.

Niño, déjame, no pises

mi blancor almidonado.

El jinete se acercaba

tocando el tambor del llano.

Dentro de la fragua el niño

tiene los ojos cerrados.

Por el olivar venían,

bronce y sueño, los gitanos.

Las cabezas levantadas

y los ojos entornados.

¡Cómo canta la zumaya, ay cómo canta en el árbol!

Por el cielo va la luna

con un niño de la mano.

Dentro de la fragua lloran,

dando gritos, los gitanos.

El aire la vela, vela.

El aire la está velando.

En ámbolos dous poemas escóllese a noite como espacio escénico: unha noite andaluza, caracterizada polas súas fragancias, ou unha noite galega, na que a escuridade xera un peculiar mundo de sombras. As dúas noites son atemporais, as dúas son fermosas, e cada unha constitúe un marco idóneo para un pasamento que, ó entenderse como parte do acontecer natural do cosmos, é susceptible de idealización estética.
A análise do léxico empregado nestas dúas danzas da morte pon de relevo que ambas proceden dunha idéntica concepción do tema:

- "Danza da lúa en Santiago": 38 palabras dotadas de contido léxico, das que 21 son sustantivos, 8 adxectivos e 9 verbos: ar, boi, ceo, corpo, filla, froles, galán, lobos, lúa, nai, nubens, ollos, ouro, pedra, porta, potro, somas, sono, toxos, vidros, xemido; branco, coroada, cheo, grises, inmenso, melancónico, negro, transido, triste; bailar, bruar, deixar, ferir, fitar, morrer, ollar, soñar.

- "Romance de la luna, luna": 54 palabras dotadas de contido léxico, das que 28 son sustantivos, 9 adxectivos e 17 verbos: aire, anillos, árbol, blancor, brazos, bronce, caballos, cabezas, cielo, collares, corazón, fragua, gitanos, gritos, jinete, luna, llano, mano, nardos, niño, olivar, ojos, polisón, senos, sueño, tambor, yunque, zumaya; acercar, bailar, cantar, dar, dejar, encontrar, enseñar, hacer, huir, ir, llorar, mirar, mover, pisar, sentir, velar, venir; almidonado, blanco, cerrados, conmovido, duro, entornados, levantadas, lúbrica, pura.

Obsérvase un léxico máis ricaz no "Romance de la luna, luna", feito que se explica na liberdade de selección con que actúa García Lorca ao poetizar na lingua que domina. Con todo, as palabras clave de cada texto son as mesmas, todas elas empregadas cun alto índice de frecuencia na obra en castelán deste poeta:

$$
\begin{gathered}
\text { lúa/luna } \\
\text { bailar/bailar } \\
\text { branco/blanco }
\end{gathered}
$$

Existen, certamente, diferencias entre os dous poemas, pero non van máis alá do que se pode entender como rasgos accidentais condicionados polo distinto entorno xeográfico e cultural desde o que xorde cada resposta lírica. En virtude xustamente destas diferencias, a "Danza da lúa en Santiago" é un poema galego, con resoancias que se remontan á estética dos Cancioneiros medievais ou á concepción existencial de Rosalía de Castro, e o "Romance de la luna, luna" é un poema andaluz.

A explicación desta capacidade mimética reside no propio carácter de Federico García Lorca, que Jorge Guillén define con estas palabras: 
Lo sabe todo el mundo, es decir, en esta ocasión el mundo entero: Federico García Lorca fue una criatura extra ordinaria.

"Criatura" significa esta vez más que "hombre". Porque Federico nos ponía en contacto con la creación, con ese conjunto de fondo en que se mantienen las fuerzas fecundas, y aquel hombre era ante todo manantial, arranque fresquísimo de manantial, una transparencia de origen entre los orígenes del universo, tan recién creado y tan antiguo. Junto al poeta -y no solo en su poesía- se respiraba un aura que él iluminaba con su propia luz. Entonces no hacía frío de invierno ni calor de verano: "hacía... Federico". Pero no por acumulación de originalidades, sino por originalidad de raíz: criatura de la Creación, inmersa en Creación, encrucijada de Creación y participante de las profundas corrientes creadoras. Por tanto, nadie con más naturalidad poeta, y no sólo en la cima del verso.

\section{$* * *$}

Federico García Lorca, que ó longo de toda a súa etapa andaluza experimenta e domina a arte menor en tódalas súas posibilidades, é, a partir de 1928, un virtuoso do romance, de maneira moi especial na súa modalidade narrativa. En efecto, os dezaoito romances que constitúen o Romancero Gitano pódense entender coma a proba definitiva da identificación entre o poeta máis xenuinamente popular da avangarda española e a estrofa secularmente empregada polo pobo.

Recolle o Romancero gitano, dada a súa amplitude e a súa mestría, tódalas clases de octosílabos. Pero Lorca afástase desa preferencia case unánime dos poetas casteláns -desde o Romancero viejo ata Antonio Machado- polos octosílabos de ritmo binario impar, do tipo '- $-\dot{-}-\dot{-}-$ :

Caminante, son tus huellas el camino, y nada más; caminante, no hay camino, se hace camino al andar. $\mathrm{Al}$ andar se hace camino, y al volver la vista atrás se ve la senda que nunca se ha de volver a pisar. Caminante, no hay camino, sino estelas en la mar.
Afastándose da liña xeral da poesía española en metro curto, dá entrada na súa obra, en paridade cos octosílabos de ritmo binario par, ós de ritmo binario par, do tipo $--_{-}^{\prime}--_{-}--$:
Antonio, ¿quién eres tú?
Si te llamaras Camborio, hubieras hecho una fuente de sangre con cinco chorros.
Ni tú eres hijo de nadie, ni legítimo Camborio.

e ós de ritmo ternario, na súa variedade dactílica, denominados de gaita gallega na métrica castelá por crearen uns períodos de tempos marcados e non marcados que coinciden cos que se producen no acompañamento das foliadas,

$\dot{-}--\dot{-}--\dot{-}-$ :

\section{Voces de muerte sonaron cerca del Guadalquivir. Voces antiguas que cercan voz de clavel varonil.}

Estes versos acadan multitude de rexistros musicais e evocadores na combinación simultánea da súa cadencia acentual con recursos pertencentes a outros niveis de lingua. Poderíamos dicir que a fórmula maxistral do octosílabo lorquiano é, na maioría dos casos, esta: ritmo acentual + selección fónica + metáfora.

El jinete se acercaba tocando el tambor del llano.

Deste xeito, a musicalidade debida a tempos marcados e non marcados poténciase con aliteracións ou onomatopeias, ó mesmo tempo que se abre unha ampla gama de suxerencias polos vieiros da metáfora. Observemos, a título de exemplo, a complexidade de recursos que conteñen e a variedade de matices que expresan, versos coma estes:

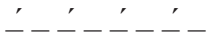

¡Compadre! ¿Dónde está, dime?

¿Dónde está tu niña amarga?

¡Cuántas veces te esperó!

¡Cuántas veces te esperara, cara fresca, negro pelo, en esta verde baranda! 


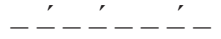

Ya suben los dos compadres hacia las altas barandas.

Dejando un rastro de sangre.

Dejando un rastro de lágrimas.

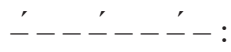

Cobre amarillo, su carne, huele a caballo y a sombra. Yunques ahumados sus pechos gimen canciones redondas.

Así, o sinxelo paradigma métrico de versos octosílabos asonantados nos pares enriquécese por obra e gracia do talento poético de Lorca ata ofrecer unha insólita posibilidade de rexistros, que se van axeitando en perfecta harmonía ás situacións interiores dos personaxes que aparecen no libro, á calidade das voces do cosmos que se perciben en cada situación e ás particulares suxerencias líricas que connotan cada pasaxe.

En Seis poemas galegos descóbrese, como queda dito, o autor do Romancero gitano e, no que respecta a métrica e ritmo, obsérvase un claro predominio do octosílabo, que flúe con naturalidade, acolléndose na maioría dos casos a combinacións próximas ó romance, con rima asonante e alterna. Desde o "Madrigal á cibdá de Santiago", onde doce versos homeopolares -octosílabos e pentasílabos- se estructuran en catro estrofas do tipo

Olla a choiva pola rúa,

laio de pedra e cristal.

Olla no vento esvaído

soma e cinza do teu mar.

ata a "Danza da lúa en Santiago", da que nos ocuparemos con maior atención máis adiante, soamente nun poema, o "Noiturnio do adoescente morto", aparecen versos de arte maior. E soamente en dous, este "Noiturnio" e maila "Canzón de cuna pra Rosalía Castro, morta", obsérvanse combinacións estróficas que se afastan do modelo $-a-a$. Con todo, o único romance perfecto na totalidade do poemario é, paradoxicamente, a "Cantiga do neno da tenda", que se diferencia das outras cinco composicións por un tema e unha actitude que a sitúan na liña de Poeta en Nueva York:

\author{
$[\ldots]$ \\ Foise pra veira do río, \\ veira do Río da Prata. \\ Sauces e cabalos múos \\ creban o vidro das ágoas. \\ Non atopou o xemido \\ malencónico da gaita, \\ non víu o inmenso gaiteiro \\ coa boca frolida de alas. \\ Triste Ramón de Sismundi, \\ veira do Río da Prata, \\ víu na tarde amortecida \\ bermello muro de lama.
}

Non hai, xa que logo, nos Seis poemas galegos un propósito de indagación rítmica, ou sexa, o feito de poetizar nunha lingua nova non leva a Federico García Lorca a experimentar nas posibilidades rítmicas desta lingua desde novos metros. O que fixo o granadino foi, simplemente, render homenaxe a Galicia desde as súas facultades innatas de poeta da intuición e desde as posibilidades adquiridas na súa traxectoria en castelán. $\mathrm{O}$ resultado é brillante tamén neste aspecto: media ducia de poesías, lorquianas na súa feitura e galegas nos seus efectos.

No que respecta a métrica e ritmo, a "Danza da lúa en Santiago" é, ó seu xeito, un romance, aínda que o autor non respeta a isometría característica desta estrofa e combina octosílabos e heptasílabos, nun total de trinta e dous versos, dos que riman entre si os pares e quedan soltos os impares.

Os octosílabos acóllense, como no resto da obra galega e castelá de Federico García Lorca, ás diferentes variedades acentuais deste verso, tanto no ritmo binario como no ternario:

$$
\begin{aligned}
& \text { nai, a lúa está bailando } \\
& \text { olla seu transido corpo } \\
& \text { na mesma porta do sono } \\
& \text { de inmenso boi melancónico } \\
& \text { fita seu corpo transido }_{\text {vólvome branca de pronto }}
\end{aligned}
$$


Con todo, percíbese neste texto unha preferencia polos octosílabos de ritmo ternario (dactílico) superior á frecuencia de uso que amosan na obra de Lorca en castelán, e isto outorga á "Danza da lúa en Santiago" unha cadencia que coincide coa da poesía galega de trans misión oral.

Tamén de ritmo ternario, neste caso anapéstico $\left(---_{-}--\right)$, o heptasílabo que se repite a modo de refrán:

\section{na Quintana dos mortos}

O octosílabo é o verso dominante na "Danza da lúa en Santiago", nunha proporción de vinte a doce, e os trinta e dous versos de que consta a composición flúen na súa órbita, correspondendo a cada unha das cantidades diferente función na estructura total da poesía: os octosílabos son portadores do tema e os heptasílabos (que amosan soamente cinco variantes, unha delas repetida oito veces) xeneran un ritmo recorrente de resonancias cancionerís.

Estes trinta e dous versos divídense en catro unidades de significado nitidamente diferenciadas, cada unha de oito versos e bimembre, de tal maneira que os versos 1 e 2 aportan un comunicado, os versos 3 e 4 constitúen un refrán, os versos 5 e 6 repiten o comunicado de 1 e 2, e os versos 7 e 8 repiten o refrán. Na cuarta e oitava posición de cada unha destas unidades aparece o heptasílabo na "Quintana dos mortos" que remata atraendo á súa cantidade os catro versos finais do poema e, en consecuencia, afastando o segundo membro da cuarta unidade de significado do que é a tónica de medida e ritmo da composición.

Todos estes artificios, que quedan salientados na peculiar disposición tipográfica, outorgan á "Danza da lúa en Santiago" unha falsa apariencia de cantiga medieval. En efecto, sendo antes que outra cousa un romance, parece outra cousa antes que un romance. Parece unha estrofa paralelística:

¡Fita aquel branco galán, olla seu transido corpo!

É a lúa que baila na Quintana dos mortos.
Fita seu corpo transido, negro de somas e lobos.

Nai, a lúa está bailando na Quintana dos mortos.

Este é o resultado da capacidade mimética e da hiersensibilidade de Federico García Lorca para intui-las voces do cosmos, que se manifestan agora na creación dos ritmos axeitados para a traducción poética desas voces.

Esta transmutación dos efectos propios dunha estrofa non é recurso frecuente en Federico García Lorca, pero tampouco non faltan precedentes. O romance número 6 do Romancero gitano, "La casada infiel", amosa unha irregularidade con respecto ó que é habitual na distribución das rimas nesta estrofa: riman entre si os versos impares e quedan soltos os pares. Pero non se trata dun xogo de versificador hábil en procura de orixinalidades efectistas, senón dunha proba da identificación de Lorca co folclore andaluz. Se, facendo caso omiso dunha disposición tipográfica que presenta os primeiros dezanove versos deste romance coma unha unidade de significado, afastámo-los tres versos iniciais dos seguintes, a aparente irregularidade de "La casada infiel" transfigúrase e o romance acada unha nova posibilidade de lectura:
Y que yo me la llevé al río creyendo que era mozuela, pero tenía marido.
Fue la noche de Santiago y casi por compromiso. Se apagaron los faroles y se encendieron los grillos. En las últimas esquinas toqué sus pechos dormidos y se me abrieron de pronto como ramos de jacintos. [...]

Trataríase así dun poema en dúas partes, no que os tres versos iniciais recollerían en forma de soleá $(a-a)$ unha sentencia popular e os cincuenta e dous restantes exemplificarían e matizarían esa sentencia, fluíndo con toda regularidade, de acordo co paradigma de rima alterna nos versos pares. 
Non hai, pois, nada radicalmente novo nos Seis poemas galegos, nada que non teña o seu precedente na obra lorquiana anterior a 1932, e, a pesar disto, son galegos, debido precisamente ó andalucismo do seu autor. Para Ortega y Gasset "el andaluz tiene un sentido vegetal de la existencia y vive co preferencia en su piel. El bien y el mal tienen ante todo un sentido cutáneo: bueno es lo suave, malo lo que roza asperamente".

Desde esta peculiaridade do carácter andaluz, do que Lorca foi o máis alto e xenial exponente poético, enténdese a conmoción interior que produciu nel unha natureza viva e omnipresente, radicalmente distinta da andaluza, que se expresa así no "Madrigal á cibdá de Santiago":

$$
\begin{aligned}
& \text { Soma e cinza do teu mar } \\
& \text { Santiago, lonxe do sol. } \\
& \text { Ágoa da mañán anterga } \\
& \text { trema no meu corazón. }
\end{aligned}
$$

E xa, gozosamente inmerso neste entorno, déixase levar polo seu feitizo e faise galego na súa resposta poética: galego nas vivencias, galego na fala e galego incluso nas resonancias rítmicas dos Seis poemas galegos. 